\title{
Sexualidade das Mulheres em Tratamento com Câncer de Colo Uterino
}

\author{
Sara Araújo de Morais ${ }^{1}$; Raimunda Tânia Pinheiro de Oliveira ${ }^{2}$; Evellyne Lemos de Moura Martins ${ }^{3}$; \\ Hermes Melo Teixeira Batista
}

Resumo: O presente estudo almejou investigar e conhecer os sentimentos envolvido em relação a sexualidade das mulheres em tratamento com câncer de colo uterino, analisando o parâmetro de avaliação das mudanças ocorridas na vida sexual após o diagnostico de câncer de colo de útero. A neoplasia do colo de útero é uma doença crônico-degenerativa mais temida, em razão do seu alto grau de letalidade e mortalidade. Trata-se de um estudo de caráter descritivo com abordagem qualitativa, desenvolvido no centro de referência regional a pacientes oncológicos do Hospital e Maternidade São Vicente de Paula. O estudo foi realizado com 14 mulheres presentes na referida unidade, sendo coletados dados no período de setembro a outubro de 2010, onde se obteve os dados através de uma entrevista composta por 8 perguntas. No entanto, através da realização da pesquisa, pode-se observar (comprovar) as alterações no padrão da sexualidade das mulheres acometidas com o câncer uterino, sendo ao fatores psicológicos, os efeitos do tratamento, o choque do diagnóstico e o impacto na relação conjugal as principais dificuldades que traz influências sentimentais de angustia frente a doença. A análise das expressões das participantes favoreceu a identificação do desinteresse sexual após o diagnóstico e durante o tratamento, comprovando a necessidade de uma assistência profissional voltada a percepção dessas mulheres sobre a vida conjugal e principalmente aos aspectos psicológicos afetados com a identificação da patologia como a alteração na imagem corporal, mudanças de papeis no seio familiar, o medo frente a morte e a sensação de incapacidade e dependência foram identificados como fatores emocionais importantes que influenciam no tratamento da patologia. Conclui-se que se deve mostrar as mesmas através da assistência psicológica que o fato de ter sido acometida com o câncer de colo de útero não lhe foi tirado o direito de dar continuidade a vida.

Palavras-Chave: sexualidade; câncer de colo de útero; fatores psicológicos

\section{Sexuality Of Women In Treatment With Colon Uterine Cancer}

\begin{abstract}
This study aimed to investigate and understand the feelings involved in sexuality of women treated with cervical cancer, analyzing the endpoint of change in sexual life after the diagnosis of cancer of the cervix. The cancer of the uterine cervix is a chronic degenerative disease most feared, because of its high mortality and mortality. This is a descriptive study with a qualitative approach, developed at the regional referral center for cancer patients under the Maternity Hospital and St. Vincent de Paul. The study was conducted with 14 women present in the unit to collect data for the period September-October 2010, where he obtained the data through an interview consisting of eight questions. However, through this research, we can see (prove) the changes on the sexuality of women afflicted with uterine cancer, and the psychological factors, the effects of treatment, the shock of diagnosis and the impact on the marital relationship main difficulties is influenced by feelings of anxiety before the illness. The analysis of the expressions of the participants favored the identification of sexual disinterest after diagnosis and during treatment, confirming the need for a dedicated professional assistance to these women's perception about married life and the psychological aspects mainly affected with the identification of pathology as the change body image, changing roles within the family, the fear in the face of death and sense of powerlessness and dependence were identified as important emotional factors that influence the treatment of lymphedema. It follows that we should show the same through psychological care that the fact of having been stricken with cancer of the cervix it was not taken the right to continue life.
\end{abstract}

Keywords: sexuality; cervical cancer; psychological factors

\footnotetext{
${ }^{1}$ Bacharelado em Enfermagem pela Faculdade Leão Sampaio. Especialista em Urgência e Emergência no atendimento pré-hospitalar pela Faculdade leão Sampaio; Especialista em Saúde da Família pela faculdade Integrada de Patos. Cursando especialização em Auditoria no sistema de saúde.

${ }^{2}$ Graduação em Ciências pela Universidade Regional do Cariri (1999) Professora Msc. da Faculdades Integradas de Patos (FIP) e Universidade Estadual do Vale do Acaraú (UVA).

${ }^{3}$ Bacharelado em Enfermagem pelo Centro Universitário UNINOVAFAPI Teresina Piaui Especialista em Terapia Intensiva (UTI) pela mesma instituição supracitada..

${ }^{4}$ Graduação em Medicina pela Universidade Federal do Ceará (1997). Medico do Hospital Regional do Cariri. Título de Especialista em Anestesiologia pela Sociedade Brasileira de Anestesiologia desde 2004. Mestrando em Ciências da Saúde pela Faculdade de Medicina do ABC. E-mail: hermesmelo@oi.com.br.
} 


\section{Introdução}

O câncer é uma neoplasia que ataca os processos básicos da vida na célula, alterando o genoma (o complemento genético total) da mesma devido a várias mutações, produzindo crescimento desordenado e invasivo das células cancerosas adentre os tecidos normais. Entretanto existem fatores que aumentam a probabilidade do câncer como: a radiação ionizante, certos tipos de substâncias químicas chamadas de carcinogênicos, determinados vírus, irritação por processos físicos e predisposição hereditária (GUYTON, 2006).

"A neoplasia do colo do útero é o câncer mais freqüente nos países em desenvolvimento, e o segundo mais incidente em todo mundo, correspondendo aproximadamente a $12 \%$ dos tumores em mulheres". Sendo responsável por 280.000 óbitos por ano no mundo, ficando atrás apenas da neoplasia maligna da mama.(NETTO; RIBALTA; MARTINS, 2005, P.9).

Partindo da temática mencionada dessa neoplasia, nota-se que não é fácil para as mulheres acometidas com o câncer aceitarem a doença; é aí então que entram as questões psicológicas das pacientes (SAMPAIO, 2008), pois descobrir-se com uma doença não é fácil tanto para o individuo como para sua família, muito menos quando se trata de uma doença crônica- degenerativa e de tratamento prolongado.

$\mathrm{O}$ tratamento torna-se então a única ferramenta para a expectativa de vida dessas mulheres, uma vez que ele pode retirar o medo de morrer e aliviar os desconfortos causados pela patologia; contudo a terapia oncologia não é fácil, isso porque a forma de administração é determinada de acordo com o estágio da doença.

Percebe-se que durante a realização de atividades multidisciplinares como: rodas de conversa, anamnese, exame físico e assistência psicológica as pacientes e médicos evitam muito falar dos efeitos do tratamento do câncer sobre a sexualidade; isso se deve a falta de conhecimento, mitos e tabus, orientação e desinformação sobre o assunto. No entanto observa-se que há queixas quanto, à insatisfação sexual, dúvidas e abandonos por seus maridos, os quais alegam medo de se contaminar ou machucá-las (BERNARDO et al, 2007).

Nesse momento de busca pela cura o entusiasmo encontra-se quase que oculto isso porque a mulher vê-se em uma situação delicada tanto por questões pessoais como também na sua vida conjugal e familiar na qual um dos pontos mais afetados na vida de uma mulher com câncer de colo uterino é o aspecto sexual. Como ela lida com as questões da sua própria sexualidade ao diagnóstico de câncer uterino?

Justifica-se a necessidade de investigar o aspecto da sexualidade em pacientes acometidas com câncer uterino em função dos índices epidemiológicos da doença entre as mulheres que cresce de 
forma alarmante comprometendo a qualidade de vida e o tempo de vida das mesmas e a presença restrita de estudos na área que tratem dessa especificidade: sexualidade.

A realização dessa pesquisa é, portanto de relevância imensurável, tendo em vista que há poucos estudos que tratam da relação entre câncer e sexualidade, sendo assim, este trabalho oferece uma possibilidade para contribuir com estudos na área e fomentar novos questionamentos para futuras pesquisas. Avaliando assim a sua fragilidade como um ser feminino em relação à doença abordando a sexualidade no processo da patologia, fornecendo pontos essenciais para a assistência a essas mulheres.

\section{Anatomia do sistema reprodutor feminino}

O sistema reprodutor feminino compreende a parte do corpo, mas representativa para a mulher, isto porque referencia seu sexo e suas características femininas além de ser o ponto principal de trajetória, segmento e procriação do seu significado de vida diferenciando-a do sexo masculino.

Os órgãos genitais femininos do ponto de vista da reprodução são mais complexos do que o do homem, conforme Dangelo; Fattini (2007), isso deve-se ao fato de ser composto por mais um órgão e, que evidencia a mulher a mais uma função de abrigar e propiciar o desenvolvimento do novo ser vivo, tais características refere-se ao útero.

De acordo com Miranda et. al. (2006), o útero apresenta-se como uma das suas principais funções a de sustentar, nutrir e proteger o concepto durante a gestação e, por isso, é um órgão de grande valor para o significado da feminilidade do ser mulher.

A mulher, no entanto encontra-se exposta a uma gama de fatores que influência seu padrão de saúde ginecológica isso se deve ao fato de fazer uso cotidiano de anticoncepcionais, riscos de infecções ginecológicas, hábitos higiênicos insatisfatórios, idade e vida reprodutiva. Dentre outros processos patológicos tem-se em destaque a questão dos tumores ginecológicos que constituem um grupo heterogêneo de neoplasias.

\section{Abordagem sobre o câncer}

O câncer é um dos processos patológicos que inicia-se quando uma célula anormal é modificada por mutação genética do DNA celular. Essa célula diferenciada forma um clone e inicia a proliferação de modo anormal, desprezando os sinais de regulação do crescimento no ambiente ao redor da célula. 
De acordo com Filho; Alves (2010) resume-se, trazendo as informações relatadas para o contexto temático da patologia, que as células problemáticas fogem literalmente desse padrão onde as mutações possibilitam as mesmas a se dividirem vigorosamente, mais que as células vizinhas, tornando-se a crescer e crescer aberradamente, passando a câncer.

Segundo Moraes (2007), os tumores ginecológicos compreendem um grupo heterogêneo de neoplasias, com origem em vários órgãos do aparelho genital, cada um com suas formas histológicas e comportamento biológico distintos.

O colo uterino é local freqüente de processos inflamatórios, infecciosos ou não, agudos ou crônicos. "Variações do ph, com conseqüentes alterações da flora residente, associada ou não a fatores mecânicos, como traumatismo durante o ato sexual, resultam em desequilíbrio da proliferação bacteriana e agressão ao epitélio de superfície" resultando em lesão. (MIRANDA et al., 2006, p.561).

\section{Sexualidade}

Tem-se como questão principal dessa pesquisa a sexualidade das mulheres acometidas com o câncer do colo uterino, segui-se por tanto baseado no contexto literário que inúmeros são os fatores que influenciam o padrão sexual de um individuo, envolvendo o aspecto psicossocial e físico do comportamento humano.

Defini-se, de acordo com Stuart e Laraia (2002), que a sexualidade é amplamente explicada como um desejo pelo contato, calor, carinho e amor. Envolve atrativo como olhar e conversar, dar as mãos, beijar ou o auto-prazer, e a produção de orgasmos mútuo. A sexualidade faz parte da plena sensação total de se próprio por uma outra pessoa.

Durante o tratamento para vencer o câncer, o paciente vive situações físicas que vem a interferir na sua sexualidade, isso deve-se principalmente aos efeitos das modificações e o fator emocional da paciente. Muitos desses transtornos são passageiros, já outros se apresentam diminuídos ou eliminados com a ajuda psicoterápica.

Em muitos casos de câncer de colo uterino, se faz necessário a realização da histerectomia, conforme cita Davim (2005), para várias mulheres o significado psicológico da retirada do útero encontra-se associado à manifestação psicossexual. Por tanto, a importância do útero como órgão psicossexual, modifica-se de mulher para mulher ao saber que é um órgão que desempenha as seguintes funções: estrutura utilizada para procriação, excreção, regulador e controlador do corpo, significa fonte de competência feminina, representa reservatório da força e vitalidade, visto como mantedor da juventude bem como da atração. 
Diante dessa problemática, nota-se a necessidade de oferecer o apoio psicológico a estas mulheres, com o objetivo de apaziguar e acalmar quanto ao aspecto emocional da paciente.

\section{Aspectos psicológicos}

Descobri-se com uma doença não é facilmente compreendido pelo psicológico do indivíduo, muito menos quando se trata de uma doença crônica e de tratamento prolongado crescendo a necessidade de apoio psicológico visando a restaurar ou manter a qualidade de vida.

$\mathrm{O}$ recebimento do diagnóstico comumente abala a integridade psicológica das pacientes, tornando-as fragilizadas e vulneráveis. É por tanto um momento gerador de intensa angustia, em geral, no que tange ao estigma de uma época de possibilidade da morte eminente. Nesse momento inicial de descoberta o fator mais relevante é o de negação da doença, sua ocorrência é mais freqüente nos estados graves de saúde e de estados terminais, mas este sentimento poderá voltar em outros momentos, onde o paciente utiliza esse tempo de cessação para se recuperar do choque inicial provocado pela noticia da doença, mas essa situação é comum, pois aceitar uma doença como o câncer aparenta no primeiro momento, estar-se aceitando a possibilidade de morte (BARONI, SD).

Contudo, paralelamente, abre-se um caminho de um tratamento incerto, doloroso e prolongado; que deixa seqüelas no corpo e choca à família; freqüentemente ocorre, afastamento dos amigos, fragiliza planos e coloca a paciente frente a questões mais angustiantes da existência humana: a vivência da finítude da vida, intimamente relacionada a situação de doença e questionamento entre a vida e a morte (BARONI, SD).

Outro aspecto importantíssimo de ocorrência relevante na paciente oncologica é a experiência da ansiedade, sendo uma reação normal aos eventos estressantes e traumáticos que afligem a doente com câncer uterino. Observa-se a exacerbação dessa sensação ansiosa nos momentos de crise ou de tomada de decisão, devido a espera pelo tratamento ou cirurgia; " o termino do tratamento, recorrência ou estagio terminal da doença, os sintomas de ansiedade podem se intensificar e comprometer a qualidade de vida do doente a da sua família"(Lourenço 2000 apud Crespo ; Lourenço, 2007,p.144).

Considerando toda essa temática, pode-se compreender que desde a notícia do diagnostico até o final do tratamento, as pacientes que vivenciam situações criticas passam por forte sobrecarga emocional. Vale salientar que a assistência psicológica visa fundamentalmente auxiliar estes clientes na travessia destes momentos, por meio da criação de um ambiente onde possam expressar livremente seus sentimentos e angústias relacionadas a seu quadro clinico, tornado o processo da doença e tratamento menos ameaçador (BARONI SD). 
O presente estudo teve como proposta metodológica a pesquisa descritiva, exploratória com abordagem qualitativa. A pesquisa em questão foi realizada no centro de oncologia do hospital e maternidade São Vicente de Paula (HMSVP) no município de Barbalha-ce (situado da região do Cariri a $539 \mathrm{~km}$ de Fortaleza). A coleta foi desenvolvida durante os meses de setembro e outubro de 2010, sendo solicitado o pedido de autorização para realização da pesquisa em campo no já referido hospital (Apêndice A), como também para as entrevistadas, através do termo de consentimento livre e esclarecido (Apêndice B).

A população do estudo foi formada por pacientes diagnosticadas com câncer de colo de útero, seguindo as etapas de: coleta de dados, desenvolvimento, análise e apresentação, após a emissão do parecer do Comitê de Ética em pesquisa. A amostra partiu composta por mulheres de 40 a 70 anos com câncer de colo do uterino atendidas no centro de oncologia do HMSVP no ano de 2010.

$\mathrm{O}$ instrumento de coleta de dados adotado foi uma entrevista não-estruturada, com o critério de esgotamento de dado, ou seja, a entrevista foi realizada até obter todas as informações necessárias; A mesma foi registrada escrevendo todo o depoimento após o consentimento da mulher. Foram transcritos os discursos das pacientes e depois analisados cuidadosamente.

Os dados foram categorizados em eixos temáticos de acordo com a pergunta realizada e a afinidade entre as respostas. Os dados foram coletados até ocorrer a repetição de respostas evidenciando a saturação da pesquisa, obtendo um total de 14 Participantes. Os relatos das entrevistadas foram reproduzidos fielmente e em seguida foram analisados e interpretados, para então serem reunidos e organizados de acordo com finalidade entre as respostas dadas a perguntas subjetivas e os aspectos observados.

Contemplando aos aspectos éticos da pesquisa com seres humanos conforme institui a resolução 196/96 do conselho nacional de saúde onde foi entregue um termo de consentimento livre e esclarecido para cada participante da pesquisa.

\section{Resultados e Discussões}

O presente estudo teve por finalidade analisar a sexualidade das mulheres após o diagnóstico e tratamento do câncer de colo de útero, no Hospital e Maternidade São Vicente de Paula. Discutir sobre esse temática é difícil, pois envolve uma série de fatores relacionados com o tema. Fatores emocionais, sociais, psicológicos, culturais, sexual e familiar. Foram entrevistadas 14 pacientes, e realizada com 
cada uma delas uma entrevista com oito perguntas acerca da percepção e sentimentos em relação à doença.

Através da analise realizada pode-se identificar que a população selecionada foi diversificada em todas as variáveis escolhidas, dando a pesquisa uma característica interessante, uma vez de abrange uma variedade em termos de faixa etária, escolaridade, estado civil, escolaridade e renda.

Como pode-se notar, a faixa etária das entrevistadas é diversificada, situando-se entre 40 a 70 anos. Sendo que metade relataram ter entre 60 a 70 anos, e a outra metade referiram ter entre 40 e 59 anos. Graças a essa coincidência dos resultados favoreceu a pesquisa no seguinte fato, de ter uma população que represente uma faixa etária diversificada em idade. Quanto ao estado civil das entrevistadas, observou-se que $43 \%$ das mulheres são casadas e $36 \%$ são viúvas. Dentre elas somente 14,2\% são separadas e $7 \%$ solteira. Em relação ao critério de escolaridade 50\% apresentam ensino fundamental incompleto, tendo ensino médio completo $21 \%$ das participantes; Somente $7 \%$ tem nível superior completo e $14,2 \%$ nunca estudos.

Avaliando a variável renda familiar, foi detectado que $57 \%$ da amostra, tem renda de 1 salário mínimo, 35\% adquirem 2 salários mínimos e apenas $7 \%$ possuem 4 salários mínimos mensalmente. Adiante segui-se uma avaliação em relação da escolaridade e renda familiar e a realização do exame de prevenção, assim como também será avaliado de acordo com os discursos a temática em questão, analisando os depoimentos para se atingir os objetivos do trabalho.

A interpretação dos dados colhidos favoreceu a elaboração de 2 categorias: Mudanças em relação à sexualidade após o diagnostico do C.A; Impacto na relação conjugal.

\section{Mudanças em relação à sexualidade após o diagnostico do C.A}

A sexualidade é um dos pilares para a construção da boa qualidade de vida, onde a atividade sexual constitui um dos índices que propicia ânimo a vida, podendo por isso constituir motivo de alegria ou tristeza com todas as suas nuances na vida da mulher.

De acordo com Bernardo (sd) durante o tratamento de luta contra o câncer, a paciente vive situações físicas que podem interferir na sua sexualidade. Percebe-se nas falas abaixo que diante do exposto a paciente relata após a descoberta do câncer de colo uma situação vivenciada por elas de disfunção sexual na vida conjugal.

\footnotetext{
“Eu não quis mais ter relação com meu marido, depois da notícia. Eu não tive, mas cabeça para essas coisas sabe, mas eu continuei tendo a companhia dele ".'(gardênia);

"A cabeça deu um nó e não tinha condições psicológicas, nem eu nem ele, mas ainda aconteceu umas 2 vezes”. (lírio);
} 
Observa-se nos relatos acima, que o fator psicológico esteve à frente, impedindo de agir e pensar pelo próprio desejo sexual. O impacto da noticia, as mudanças com a descoberta da patologia, o novo estilo de vida e a forma de encarar a doença, são variáveis que estão a influenciar a sexualidade dessas mulheres.

Esse lado intimo e belo deixa de existir, passando a ser um fato preocupante para as mulher acometidas com o câncer uterino, isso torna-se evidente pelas falas a seguir:

\section{"Perdi o interesse o sexo pra mim não teve mais significado" (cacto);}

Além do aspecto emocional abalado, existem ainda as alterações fisiopatológica advindas com o câncer, como o sangramento vaginal durante e após a relação, dor no ato sexual e hipersensibilidade da genitália.

A disfunção sexual é uma experiência esperada com o diagnóstico do câncer uterino e vivenciada pelo casal como uma situação preocupante para ambos, onde elas sentem-se abandonadas, devido a doença, tendo como frustração maior o medo de perder o parceiro por não poder ter e oferecer uma vida sexual ativa.(BERNARDO sd).

Percebi-se nessa categoria aparte dos relatos acima, que a vida conjugal, é envolvida de problemas, tristezas, incertezas, dificuldades, momentos e experiências vividas no cotidiano. Onde observou-se que é nessa situação de doença, que o afeto e o carinho se fazem necessário por parte do parceiro, sendo este uma fonte de apoio, esperança e incentivo de cura.

\section{Impacto na relação conjugal.}

$\mathrm{O}$ afeto matrimonial, representa muito mais do que o simples significado de casar-se, representa amor, afeto, companheirismo, amizade e respeito. A relação conjugal nada mas é do que a convivência e dedicação existente entre o homem e a mulher, dividindo assim os bons momentos de felicidade, tristeza, dificuldades e tudo o que a vida proporciona a um casal.

Diante do exposto, observa-se que a vida a dois é repleta de situações que os expõe a provações cotidianas de que se existe realmente amor para enfrentar as dificuldades. É nesse ponto de vista que se abre um leque de incertezas na vida de uma mulher acometida com o câncer de colo de útero, isso porque de uma forma geral, a sexualidade é um fator que está contido na vida de um casal e que de qualquer maneira irá representar para a mesma algo que a impossibilitará de desempenhar seu papel como mulher para o companheiro.

Pode-se conferir através das falas:

"Ele de inicio ficou assim, sem aceitar o que tinha me acontecido, não queria que eu fizesse o tratamento, mas ai depois ele foi me compreendendo e viu que eu tinha que me tratar." (tulipa) 
"No começo ele ficou afastado de mim, não queria muita conversa sabe, tava triste, mas eu fui tentando explicar que isso acontece e que eu não era a primeira a ter câncer de colo de útero, ai foi que ele ficou mais calmo." (Hortência);

Analisando os discursos acima, observa-se que o impulso masculino predomina diante do medo de perder a esposa, notando o ar de negação ao acometimento do câncer. $\mathrm{O}$ apoio emocional e psicológico se faz prioritário nesse momento.

Avaliando de forma geral todas as entrevistadas, é fato que a maioria das participantes afirmou que seus companheiros apesar de não terem tido mas uma vida sexual ativa, apresentaram-se compreensivos e aptos as mudanças advindas com a patologia.

"Ele compreendeu a minha situação, ficou triste um pouco, mas ansioso para que eu ficasse boa logo." (margarida);

"Ele foi compreensivo, me deu carinho, atenção, ficou mais atencioso comigo." (orquidia);

Avaliou-se também que o interesse e o envolvimento do companheiro nas consultas e seções do tratamento é de extrema importância para ambos pois diminui a ansiedade e o medo da paciente por sentir-se compreendida pelo companheiro. Para o esposo se faz importante acompanhar todo o processo porque não ira restar duvidas sobre o tratamento melhorando o envolvimento do casal.

Comprova-se esse fato pelos depoimentos:

"Ele conversava com os médicos, perguntava muitas coisas a ele, ai ele ficava até mais aliviado quando a gente vinha das consultas." (jasmim);

"Olha ele vinha para as consultas comigo. Ele tem pleno conhecimento da doença." (lírio);

Finaliza-se por tanto a análise dessa categoria, concluindo que se há o companheirismo, o respeito, carinho e atenção tudo se resume a um favorável prognóstico de cura, isso porque o apoio da família e do companheiro auxiliam a um pensamento positivo constituindo os pilares essenciais para pacientes oncológicas.

\section{Considerações Finais}

A neoplasia do colo uterino é uma doença de evolução lenta que passa da fase precursora para o câncer em um período aproximado de 10 anos. Contraditoriamente a alarmante estática do câncer de colo, ele é o único câncer para o qual se dispõe de técnicas para prevenção, detecção precoce e tratamento eficaz. 
Quanto mais precoce for o diagnóstico e a intervenção, maior a chance de sobrevivência da mulher, tornando mínima a duração do tratamento, menos agressivo e de menores custos. O controle do câncer cervico-uterino obedece a estratégias de prevenção secundaria, baseada na citologia cervical, mas que ainda representa um instrumento de resistência pela população feminina na adesão ao exame.

O diagnóstico e o tratamento dessa patologia marcam a vida de uma mulher, por o processo da doença se dar em uma região que representa a feminilidade do sexo em questão, uma vez que, a sexualidade é vista como forma de prazer, amor e afeto sentidos entre duas pessoas e que essa visão altera-se após o diagnóstico do câncer.

Diante do exposto, o estudo em questão, teve o objetivo de investigar qual a visão diante da sexualidade para as mulheres acometidas com o câncer cervical, no ponto de vista de que após atingir a maturidade física, a sexualidade se torna uma necessidade humana básica de todo individuo que pelo quadro patológico da doença passa a não ser vista mas como um ato de prazer; e como seria visto então o ato sexual após o impacto do diagnóstico?

Constatou-se, porém que a disfunção sexual é fato relatado e conseqüentemente esperado em uma paciente oncológica surpreendidas como câncer de colo de útero. Isso devi-se a vários fatores, um deles a questão do próprio tratamento que exige uma certo período de abstinência sexual para se alcançar um bom resultado no tratamento. Por outro lado identificou-se que o lado emocional ocasiona influências no desempenho sexual das pacientes.

Conclui-se com a finalização da análise de cada categoria que o aspecto psicológico é um fator determinante no padrão de qualidade da vida de uma pessoa enferma e é este o ponto que precisa de uma maior intervenção e atenção por parte dos profissionais que prestam assistência a pacientes oncológicas.

Esse trabalho contribuirá de forma significativa para os possíveis estudos que venha a surgir com a temática em questão no intuito de servir como fonte literária abordando os principais anseios que permeiam a vida de uma mulher com câncer de colo; assim como também contribuirá para os profissionais da área da saúde que lida com essa clientela, pois a pesquisa abordou de forma clara e objetiva as fundamentais necessidades de uma paciente acometida com o câncer de colo, propiciando uma melhor assistência holística não só para a cliente, mas também a família como no geral.

\section{Referencias}

BARONI, C.F. O câncer e o processo emocional. Pós graduação em Latu- sensu em psicanálise pela PUC/São Paulo.

BERNARDO, B.C et al. Disfunção Sexual em pacientes com câncer do colo uterino avançado submetidas à rabioterapia exclusiva. Revista Brasileira de Ginecol Obstet. V.29, n², p.85-90, 17 jan. 2007. 
CRESPO, A.S.;LOURENÇO, M.T.C.; O impacto psicológico da doença. In: MOHALLEM G.C, RODRIGUES A.B. Enfermagem Oncológica. São Paulo: Manole, 2007.

DANGElO, J.G, FATTINI C.A. Sistema Genital Feminino. Anatomia Humana Sistêmica e Segmentar. São Paulo: Atheneu, 2007.

DAVIM, R.M.B. et al. Percepção de mulheres quanto a histerectomia. Revista Nursing, vol.89.n8. outubro, p-484-490,2005.

FILHO, A.L; ALVES, V.A.F. Neoplasias. In: FRANCO, M et al.Patologia: processos gerais.5ed. São Paulo: Atheneu, 2010.

GUYTON, A.C, HALL, H.E. Controle Genetico da síntese de proteínas, Função celular e Reprodução Celular. Tratado de Fisiologia Medica. 11 ed, Rio de Janeiro: Elsevier, 2006.

MIRANDA,D. et al. Sistema genital feminino.In: FILHO, G.B. BOGLIOLO Patologia.7ed. Rio de Janeiro:Guanabara Koogan, 2006.

MORAES, M.W. Cancer ginecológico. In: MOHALLEM G.C, RODRIGUES A.B. Enfermagem Oncológica. São Paulo: Manole, 2007.

NETTO A.R, RIBALTA J.C.L, MARTINS N.V. Estado atual da prevenção do câncer do colo uterino no Brasil. In: MARTINS N.V, RIBALTA J.C.L. Patologia do Trato Genital Inferior. São Paulo:Roca, 2005.

SAMPAIO A.S. Apoio psicológico ao paciente com câncer.(s.d). Disponível em: www.oncoguia.com.br. Acesso em: 09 abril. 2008.

STUART, G.W.; LARRAI, M.T. Respostas sexuais e distúrbios sexuais. In: Enfermagem Psiquiatrica. Rio de Janeiro, Reichamam e Afonso, 4ed. 2002.

Como citar este artigo (Formato ABNT):

MORAIS, S.A.; OLIVEIRA, R.T.P.; MARTINS, E.L.M.; BATISTA, H.M.T. Sexualidade das Mulheres em Tratamento com câncer de Colo Uterino. Id on Line Revista de Psicologia, Fevereiro de 2015, vol.9, n.25, p. 91-101. ISSN 1981-1189.

Recebido: 10/01/2015

Aceito:24/01/2015 